\title{
A Prospective Evaluation of Tru-Cut Biopsy and Fine-needle Aspiration Cytology in Male Breast Cancer Detection
}

\author{
CHIARA ADRIANA PISTOLESE ${ }^{1}$, TOMMASO PERRETTA ${ }^{1}$, GIULIA CLARONI $^{1}$, LUCIA ANEMONA $^{2}$, \\ FRANCESCA SERVADEI $^{2}$, ALBERTO COLLURA ${ }^{1}$, MICHELA CENSI $^{1}$, MARCO MATERAZZO $^{3}$, \\ MARCO PELLICCIARO ${ }^{3}$, FELICIANA LAMACCHIA $^{1}$ and GIANLUCA VANNI ${ }^{3}$ \\ ${ }^{1}$ Department of Biomedicine and Prevention, Division of Diagnostic Imaging, \\ Policlinico Tor Vergata (PTV) University, Rome, Italy; \\ ${ }^{2}$ Anatomic Pathology, Department of Experimental Medicine, \\ Policlinico Tor Vergata (PTV) University, Rome, Italy; \\ ${ }^{3}$ Breast Unit-Department of Surgical Science, Policlinico Tor Vergata (PTV) University, Rome, Italy
}

\begin{abstract}
Background: Male breast-cancer $(M B C)$ is often diagnosed late. Our purpose was to evaluate fine-needle aspiration cytology (FNAC) versus Tru-Cut biopsy (TCNB) in MBC diagnosis. Patients and Methods: Men with suspicious breast lesions were prospectively enrolled; 54 met the inclusion criteria and underwent FNAC and TCNB. FNAC, TCNB and gold-standard results were compared. Results: Unsatisfactory results were $11.1 \%$ after FNAC and none after TCNB ( $p=0.027)$. After gold-standard evaluation, the diagnosis of FNAC and TCNB was confirmed, respectively, in $63.0 \%$ and $98.1 \%$ and changed in $37.0 \%$ and $1.9 \%(p<0.001)$. The malignancy rate after FNAC, TCNB and surgery were, respectively, $25.9 \%, 33.3 \%$ and $35.1 \%$ ( FNAC vs. TCNB $p=0.5276$, FNAC vs. surgery $p=0.404$; TCNB vs. surgery $p=1)$. Among invasive carcinomas, $93.8 \%$ were identified by FNAC vs. $87.5 \%$ by TCNB $(p=1)$; all ductal carcinoma in situ (DCIS) were detected after TCNB and none after FNAC ( $p=0.1)$. Conclusion: FNAC leads to a significantly higher number of inadequate samplings and seems to be subject to increased DCIS misdiagnoses. TCNB correlated better to the final histological report.
\end{abstract}

The breast male tissue is mainly composed of adipose tissue,

This article is freely accessible online.

Correspondence to: Feliciana Lamacchia, MD, Department of Biomedicine and Prevention, Division of Diagnostic Imaging, Policlinico Tor Vergata (PTV) University, Viale Oxford 81, 00133, Rome, Italy. Tel: +39 0620902400, e-mail: lamacchia.feliciana@ gmail.com

Key Words: Tru-Cut needle biopsy, fine needle aspiration cytology, ultrasound, breast lesions, male cancer. a few ducts and almost no lobules $(1,2)$. Cooper ligaments are absent and the presence of terminal duct lobular units (the main site of origin for the female breast lesions) is rare (3). For this reason, lobular lesions and fibroadenomas are exceedingly rare in men (4).

Gynecomastia is the most common benign breast condition in males and it is the first cause of palpable masses (5-8). In most cases, it represents the result of an unbalanced androgen to estrogen ratio (8). Apart from gynecomastia, male breast lesions can be grouped based on histopathological type and behavior, into two main categories as "benign" and "malignant" $(9,10)$.

Male breast cancer (MBC) is a rare disease representing $1 \%$ of all breast cancers. According to many studies, MBC is diagnosed later in life, compared with female breast cancer (FBC) (11). In a large population-based study of 5,494 cases of MBC, the mean age of diagnosis was 65.8 years (12). In addition, men usually present a more advanced stage of cancer than women, owing to a delay in diagnosis. In fact, it has been reported that approximately $50 \%$ of men with breast cancer have a palpable ipsilateral axillary lymphadenopathy $(5,13-16)$. When there is positive lymph nodes and metastasis there is bad prognosis for all types of carcinoma (17-19). MBCs are usually unilateral, occurring bilaterally in less than $1 \%$ of cases $(13,14)$.

As in women, the majority of MBCs are invasive ductal carcinomas (IDC) not otherwise specified. Nevertheless, papillary carcinoma or Paget disease are also present $(20,21)$.

Clinically, MBC usually manifests as a painless mass, in most cases unilateral, with a marked tendency to infiltrate adjacent structures. Breast physical examination in men has been reported to be very sensitive, but lacks specificity in the detection of malignancy. According to the American College of Radiology, if an indeterminate breast mass is identified, the initial recommended imaging study is ultrasound (US) in 
men younger than 25 years and, in men 25 years of age and older, mammography (MMG) or digital breast tomosynthesis. If physical examination is suspicious for male breast cancer, MMG or digital breast tomosynthesis is recommended, regardless of the patient's age $(22,23)$. Bilateral MMG should always be performed and the standard mediolateral oblique and craniocaudal views should be obtained. When mammographic findings are not normal or benign, further evaluation with targeted US should be performed (24). For breast imaging-reporting and data system (BI-RADS) assessment, the protocol is identical to that used in women $(4,25,26)$. As part of the US evaluation of a suspicious finding, the ipsilateral axillary lymph nodes should also be examined, because $50 \%$ of male patients with breast cancer have axillary lymphadenopathy (10). Furthermore, US is the imaging modality of choice to perform a cytological characterization of the lesions, such as fine needle aspiration cytology (FNAC), or histological characterization, such as US-guided automated Tru-Cut needle biopsy (TCNB). FNAC has been proved to be of great value in the diagnosis of breast lumps; apart from being cost effective, it is also simple and quick while providing the cytological diagnosis. Tru-cut biopsy also known as core needle biopsy (TCNB) is now one of the useful means of obtaining histopathological diagnosis, is relatively easy and can be performed on an outpatient basis, avoiding an unnecessary excisional biopsy (27). The aim of our study was to determine the efficacy of US-TCNB and US-FNAC in the diagnosis of male breast lesions.

\section{Patients and Methods}

Study design. This prospective study was carried out at the Breast Radiology Unit of the Policlinico Tor Vergata University of Rome, between 1 January 2018 and 15 May 2020 and it was approved by the ethics committee of our University (PTV.2018). All patients signed a written informed consent for participating in the study.

All men with a recent-onset US-detectable suspicious breast lesions, having undergone mammography and US examination and addressed to our Institute for pathological characterization, were prospectively enrolled in the study. Exclusion criteria were: female sex, patients under antiplatelet and anticoagulant therapy, subjects who had to stop FNAC and/or TCNB due to bleeding, or that had not given their consent to perform both procedures, lesions $<7 \mathrm{~mm}$ (which could be difficult to sample with TCNB). We analyzed 81 male patients: 9 took antiplatelet or anticoagulant therapy, one had to stop FNAC and/or TCNB due to bleeding, 11 had findings $<7$ mm, 6 did not give their consent. Finally, 54 subjects met the inclusion criteria and were included in our study.

A new US examination was executed with high-resolution US equipment (MyLab Twice, Esaote, Genoa, Italy) and a highfrequency linear array probe $(10-13 \mathrm{MHz})$ before the procedures. For each patient, we evaluated anamnestic data (including age, family history or personal history of breast cancer), information about symptoms (nipple discharge, skin retraction, palpable nodule) and overall imaging and assigned a BI-RADS category to each lesion.
Table I. Breast Imaging Reporting and Data System (BI-RADS) category assigned to breast male findings addressed to our Tertiary Care Center for pathological characterization, with malignancy and benignity rate.

\begin{tabular}{lccc}
\hline & \multicolumn{3}{c}{ Total cases $\mathrm{n}=54(100 \%)$} \\
\hline BI-RADS category & B-IRADS 3 & B-IRADS 4 & B-IRADS 5 \\
& $(\mathrm{n}=5 ; 9.3 \%)$ & $(\mathrm{n}=35 ; 64.8 \%)$ & $(\mathrm{n}=14 ; 25.9 \%)$ \\
Malignancy rate & 0 & $5 / 35(14.3 \%)$ & $14 / 14(100 \%)$ \\
Benignity rate & $5 / 5(100 \%)$ & $30 / 35(85.7 \%)$ & 0 \\
\hline
\end{tabular}

FNAC and TCNB procedure. The procedure was performed in an ambulatory care setting by a radiologist with $>10$ years of experience in breast imaging and US-guided biopsy. All patients underwent appropriate coagulation tests before TCNB and gave their informed consent for the procedure.

FNAC and TCNB were performed with the patient in a supine position, and after a careful disinfection, the lesion was identified with the US probe. After local anesthetic administration $(10 \mathrm{ml}$ lidocaine hydrochloride), for FNAC a 21-25 gauge disposable sterile needle with $10 \mathrm{ml}$ disposable syringe is used to enter the swelling and three passes were given for all patients. TCNB was performed with a 13-gauge Tru-Cut (PRECISA ${ }^{\mathrm{TM}}$ ) and one frustule was taken at a time, and up to 5 frustules after a $5 \mathrm{~mm}$ skin incision (with a scalpel to guarantee appropriate access for a needle insertion). Thereafter, the biopsy site was compressed manually for at least 10 min until complete hemostasis. The incision site was closed with sterile adhesive skin closures and locoregional therapy with ice and antibiotics was recommended.

Cytopathological and histopathological diagnosis. Cytopathological and histopathological examinations were performed at the Anatomic Pathology Department of the Policlinico Tor Vergata Hospital (Rome, Italy).

The cytological and histological results were classified into the five diagnostic categories stipulated by the Fourth Edition of the "European Guidelines for Quality Assurance in Breast Cancer Screening and Diagnosis": C1-C5 for cytological results and B1-B5 for histological results (25). Finally, they were grouped into four categories: Unsatisfactory (B1), Benign (B2), high risk (B3), and malignant including DCIS and IDC-NOS (B4 and B5, according to the histological report).

Post-procedure management. In the case of lesions found to be malignant or classified as high-risk lesion at percutaneous biopsy, definitive surgery was performed. In case of benign diagnosis after TCNB, US follow-up after 6 months and US and mammography follow-up after 12 months were recommended. We compared the cytopathological and the histopathological results with the gold standard results after surgery or follow-up. Instrumental follow-up showing no interval change was considered as benign and gold standard result.

Statistical analysis. The cytological diagnosis after FNAC and the histological diagnosis after TCNB were correlated with gold standard results (pathological examination after surgery). Statistical analysis was performed by calculating the sensitivity, specificity, positive predictive value (PPV), negative predictive value (NPV) and diagnostic accuracy both for FNAC and TCNB. The malignancy rate 

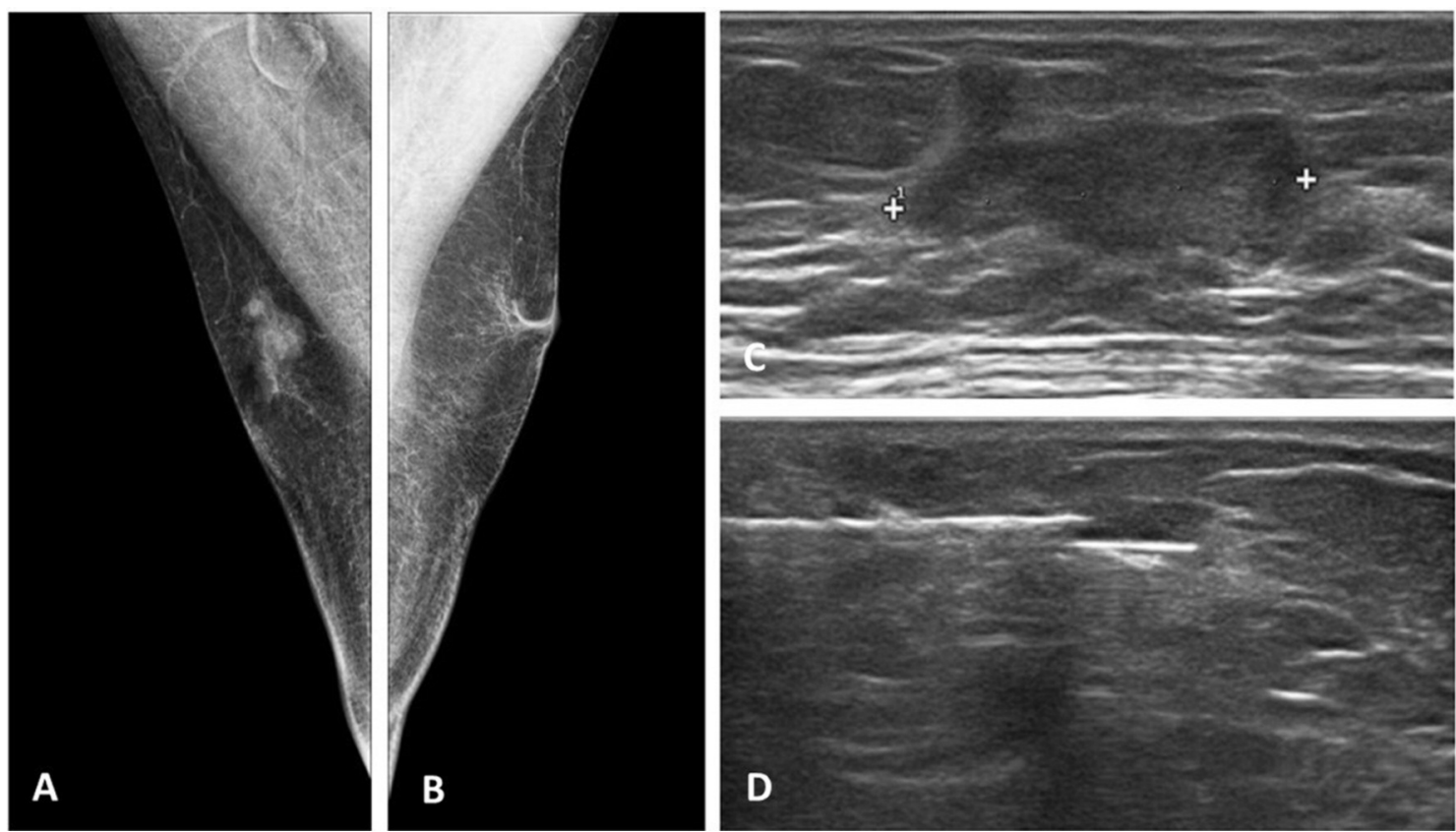

Figure 1. Mammography in mediolateral oblique projection (A and B) in a man. A partially circumscribed, irregular mass with lobulated margins is shown in the right upper peri-areolar area of the right breast. The Ultrasound (US) evaluation $(C)$ confirmed a solid hypoechoic lesion of 21.6 $\mathrm{mm}$ in maximum diameter, with irregular shape and lobulated margins. The lesion was classified as Breast Imaging-Reporting and Data System category 5. (D) US-guided Tru-cut needle biopsy of the lesion, yielding a diagnosis of B5 (C5 after fine needle aspiration cytology).

after FNAC, TCNB and surgery and the cancer underestimation rate (the ratio of the lesions diagnosed as not malignant by FNAC/TCNB and subsequently upgraded to malignant after surgery $v s$. the number of total cancers) for FNAC and TCNB, were calculated.

Descriptive and comparative statistics were performed. Summary statistics were performed for general analysis of the population frequencies and percentages were calculated for categorical variables. Data are expressed as the mean \pm standard deviation for continuous variables. Statistical analysis was performed with the Fisher's exact test. $p$-Values smaller than 0.05 were considered to indicate statistically significant differences.

\section{Results}

Study patients. Our study included 54 US detectable and palpable breast findings in 54 men (average age $=60.8$ years) (22-81). None of them had ulcerated lesions and all lesions were monolateral. All patients underwent both FNAC and TCBN and completed the study protocol. One patient had BRCA2 mutations and three had a family history of breast cancer. No personal history of previous breast cancer was recorded. Prior imaging examinations were available for 2 subjects. The mean age of males with a final diagnosis of breast cancer was 65.2 years $(58-81)$.

Complications. None of the patients had major complications after the procedures. However, 6 patients reported post procedural pain the day after the FNAC/TCNB, which was resolved with paracetamol.

BI-RADS category assessment and pathological results after FNAC/TCNB. Breast lesions were classified as following: 5 BIRADS category 3, 35 BI-RADS category 4, 14 BI-RADS category 5 (Table I). In particular, out of BI-RADS 4 lesions, two lesions were previously classified as BI-RADS category 3 and were in follow-up but, due to the increased size at 12 months follow-up, they were upgraded to BI-RADS category 4 . The breast findings had a mean maximum diameter of $24 \pm 2.3 \mathrm{~mm}$.

After FNAC, the cytopathological diagnosis was benign/reactive in 20 lesions (37.0\%), atypical/suspicious for malignancy in 14 lesions (25.9\%) and malignant in 14 lesions (25.9\%); for $6(11.1 \%)$ specimens, results were unsatisfactory and no diagnosis was made.

Following TCNB, histopathological analysis revealed: 15 (75.0\%) benign, 4 (20.0\%) high-risk and 1 (5.0\%) malignant among benign/reactive lesions after FNAC $(n=20)$. In addition, $6(42.9 \%)$ were benign, $5(35.7 \%)$ high-risk, and 3 (21.4\%) malignant among lesions atypical/suspicious for malignancy after FNAC $(n=14)$. Among non-diagnostic cases after FNAC $(n=6)$, one $(16.7 \%)$ was benign and $5(83.3 \%)$ were high-risk (Figures 1 and 2). All malignant lesions after FNAC $(n=14 ; 100 \%)$ were confirmed by TCNB; however, 3 DCIS and 1 IDC were underestimated by FNAC (Table II). 

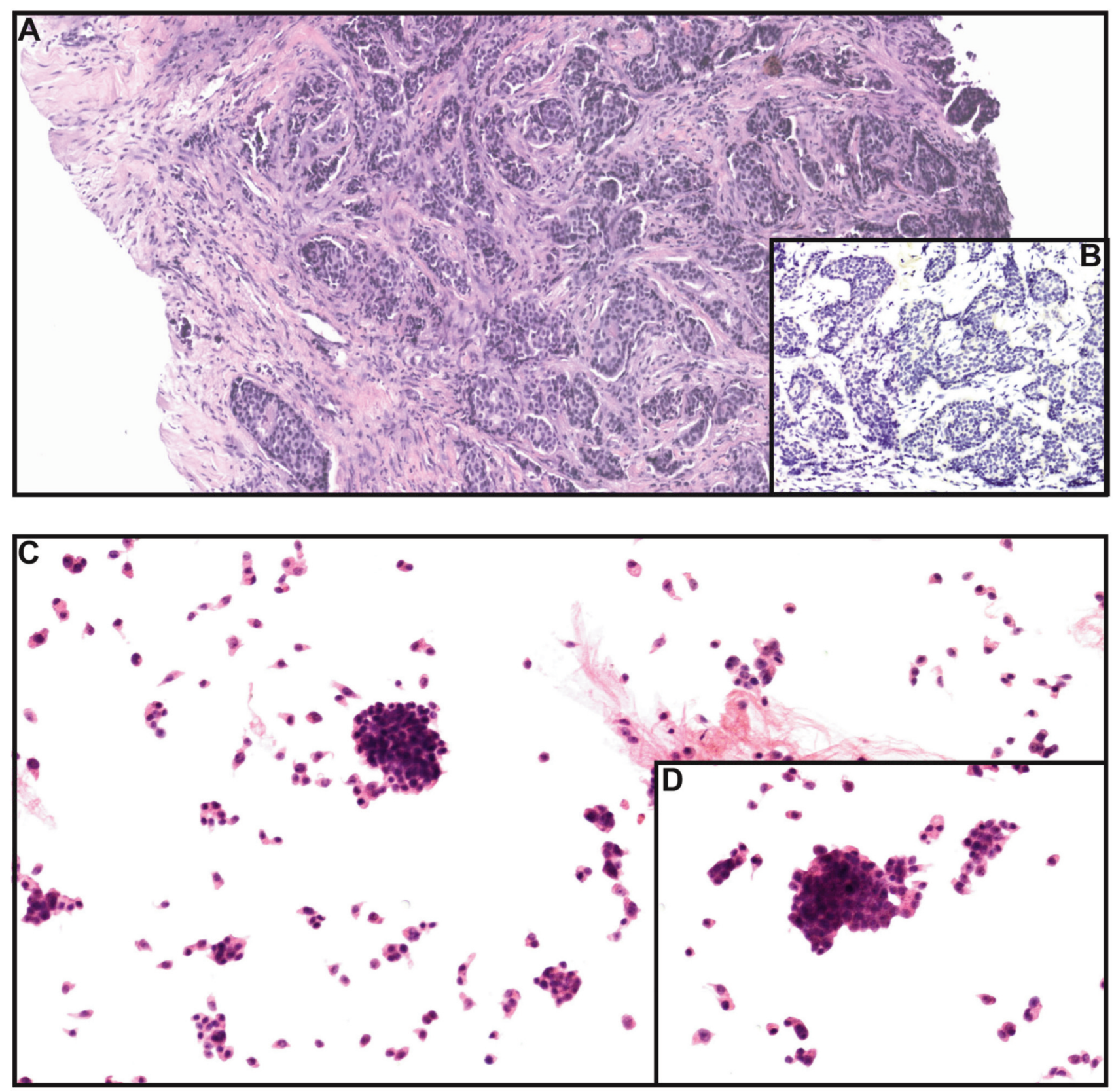

Figure 2. Histological and cytological analysis after Tru-cut needle biopsy and fine-needle aspiration cytology of the lesion shown in Figure 1. (A) Core biopsy showing ductal invasive breast carcinoma, NST, with desmoplastic stroma; it was classified as B5b according to European Guidelines $[7 x$, Hematoxylin and eosin staining $(H \& E)] .(B)$ Immunohistochemical features of $p 63$ antibody showing the absence of myoepithelial layer in the ductal structures of infiltrating carcinoma $(10 \times, H \& E) .(C, D)$ Fine-needle aspiration cytology showing poorly cohesive clusters and single neoplastic cells with large, irregular and hyperchromatic nuclei; it was classified as C5, according to European Guidelines (10x, Thin Prep, H\&E).

The results after FNAC and TCNB are compared and summarized in Table III.

Gold standard evaluation (imaging follow-up and open excision) and comparison with the cytopathological and histopathological results. Out of 22 patients with a benign finding, 15 (33.3\%) were addressed to instrumental followup and all lesions remained stable. Otherwise, 39 patients underwent surgery: 18 with a malignant lesion, 14 with a high-risk lesion, and 7 with a benign lesion including one 
Table II. The lines show histopathological results after Tru-Cut needle biopsy for each cytopathological result class after fine needle aspiration cytology. ICD, Invasive ductal carcinomas; DCIS, ductal carcinoma in situ.

\begin{tabular}{|c|c|c|c|c|}
\hline \multirow{2}{*}{$\begin{array}{l}\text { Fine needle } \\
\text { aspiration } \\
\text { cytology }\end{array}$} & \multicolumn{4}{|c|}{ Tru-Cut needle biopsy } \\
\hline & $\begin{array}{c}\text { Non- } \\
\text { diagnostic } \\
n=0\end{array}$ & $\begin{array}{c}\text { Benign } \\
\mathrm{n}=22\end{array}$ & $\begin{array}{l}\text { High-risk } \\
\mathrm{n}=9\end{array}$ & $\begin{array}{c}\text { Malignancy } \\
\mathrm{n}=28\end{array}$ \\
\hline $\begin{array}{l}\text { Non-diagnostic } \\
(\mathrm{n}=6)\end{array}$ & 0 & $1(16.7 \%)$ & $5(83.3 \%)$ & 0 \\
\hline $\begin{array}{l}\text { Benign/Reactive } \\
(\mathrm{n}=20)\end{array}$ & 0 & $15(75,0 \%)$ & $4(20 \%)$ & $\begin{array}{l}1(5 \%) \\
(1 \mathrm{ICD})\end{array}$ \\
\hline $\begin{array}{l}\text { Atypical } \\
(\mathrm{n}=14)\end{array}$ & 0 & $6(42.9 \%)$ & $5(35.7 \%)$ & $\begin{array}{c}3(21.4 \%) \\
(3 \text { DCIS })\end{array}$ \\
\hline $\begin{array}{l}\text { Malignant } \\
(\mathrm{n}=14)\end{array}$ & 0 & 0 & 0 & $\begin{array}{c}14(100 \%) \\
(14 \text { ICD) }\end{array}$ \\
\hline
\end{tabular}

with BRCA2 mutations, 3 with a family history of breast cancer, and 2 with a grown lesion during follow-up.

Comparing FNAC and TCNB with the gold standard results (surgery and follow-up), for 34/54 (63.0\%) lesions the diagnosis after FNAC was confirmed, while 20 (37.0\%) lesions changed pathological result after the gold standard evaluation, including $6 \mathrm{C} 1$ (1 turned out to be gynecomastia with simple epithelial hyperplasia and 5 were gynecomastia with atypical epithelial hyperplasia), 5 C2 (4 turned out to be gynecomastia with atypical epithelial hyperplasia and 1 IDC) and 9 C3 (6 turned out to be benign and 3 DCIS) (Table IV). Instead only $1 / 54(1.9 \%)$ lesions was, classified as high-risk after TCNB and turned out to be IDC; in the remaining cases ( $n=53 ; 98.1 \%)$, the histopathological diagnosis after TCNB was confirmed by gold standard diagnosis (Figure 3) $(p<0.001)$.

The malignancy rate after surgery was $35.1 \%$. By comparing the malignancy rate of FNAC and TCNB with the malignancy rate of surgery, we observed no significant differences (USFNAC $v s$. surgery, $p=0.404$; TCNB $v s$. surgery, $p=1$ ).

Cancer underestimation rate was $26.1 \%(5 / 19)$ for FNAC and $5.3 \%(1 / 19)$ for TCNB $(p=0.180)$.

Comparison between malignant results after FNAC and TCNB are recorded in Table V.

The FNAC showed a sensitivity of $100 \%$, a specificity of $73.7 \%$, a positive predictive value of $100 \%$ and a negative predictive value of $87.5 \%$, with an accuracy of $90.7 \%$.

The TCNB showed a sensitivity of $100 \%$, a specificity of $94.7 \%$, a PPV of $100 \%$, a NPV of $97.2 \%$, with an accuracy of $98.1 \%$.

\section{Discussion}

$\mathrm{MBC}$ is a rare condition, accounting for less than $1 \%$ of all breast carcinomas, and it's is very rare compared to female
Table III. Comparison between cytopathological results after Fine Needle Aspiration Cytology (FNAC) and histopathological results after Tru-Cut needle biopsy $(T C N B)(p<0.05)$. The "other" group includes lesions classified as atypical after FNAC and as high risk after TCNB.

\begin{tabular}{lccl}
\hline & $\begin{array}{c}\text { FNAC } \\
(\mathrm{n}=54)\end{array}$ & $\begin{array}{l}\text { TCNB } \\
(\mathrm{n}=54)\end{array}$ & $p$-Value \\
\hline Unsatisfactory & $6(11.1 \%)$ & 0 & 0.027 \\
Benign & $20(37.0 \%)$ & $18(33.3 \%)$ & 0.840 \\
Malignant & $14(25.9 \%)$ & $18(33.3 \%)$ & 0.5276 \\
Other & $14(25.9 \%)$ & $11(20.4 \%)$ & 0.648 \\
\hline
\end{tabular}

Table IV. Comparison of pathological results of 54 fine needle aspiration cytology with gold standard diagnosis (surgery; 6-12 months instrumental follow-up). The decision to address a lesion to follow-up or surgery was made by evaluating result after Tru-Cut needle biopsy, Breast Imaging Reporting and Data System category and anamnestic data.

\begin{tabular}{|c|c|c|c|c|}
\hline \multirow{2}{*}{$\begin{array}{l}\text { Fine needle } \\
\text { aspiration } \\
\text { cytology }\end{array}$} & \multicolumn{4}{|c|}{ Gold standard (surgery and follow-up) } \\
\hline & $\begin{array}{l}\text { Benign } \\
(\mathrm{n}=22)\end{array}$ & $\begin{array}{c}\text { Gynecomastia } \\
\text { with atypical } \\
\text { epithelial } \\
\text { hyperplasia } \\
(\mathrm{n}=13)\end{array}$ & $\begin{array}{c}\text { Ductal } \\
\text { in situ } \\
\text { carcinoma } \\
\quad(\mathrm{n}=3)\end{array}$ & $\begin{array}{c}\text { Invasive } \\
\text { ductal } \\
\text { carcinoma } \\
(\mathrm{n}=16)\end{array}$ \\
\hline $\begin{array}{l}\text { Non-diagnostic } \\
(\mathrm{n}=6) \\
\text { (Management) }\end{array}$ & $\begin{array}{c}1(16.7 \%) \\
\text { (follow-up) }\end{array}$ & $\begin{array}{l}5(83.3 \%) \\
\text { (surgery) }\end{array}$ & 0 & 0 \\
\hline $\begin{array}{l}\text { Benign/reactive } \\
(\mathrm{n}=20) \\
\text { (Management) }\end{array}$ & $\begin{array}{c}15(75.0 \%) \\
\text { (8 follow-up, } \\
7 \text { surgery) }\end{array}$ & $\begin{array}{l}4(20.0 \%) \\
\text { (surgery) }\end{array}$ & 0 & $\begin{array}{l}1(5.0 \%) \\
\text { (surgery) }\end{array}$ \\
\hline $\begin{array}{l}\text { Atypical } \\
(\mathrm{n}=14) \\
\text { (Management) }\end{array}$ & $\begin{array}{c}6(42.9 \%) \\
\text { (follow-up) }\end{array}$ & $\begin{array}{c}4(28.8 \%) \\
\text { (surgery) }\end{array}$ & $\begin{array}{c}3(21.4 \%) \\
\text { (surgery) }\end{array}$ & $\begin{array}{l}1(7.1 \%) \\
\text { (surgery) }\end{array}$ \\
\hline $\begin{array}{l}\text { Malignant } \\
(\mathrm{n}=14) \\
\text { (Management) }\end{array}$ & 0 & 0 & 0 & $\begin{array}{c}14(100 \%) \\
\text { (surgery) }\end{array}$ \\
\hline
\end{tabular}

breast cancer $(4,28-31)$. Usually MBC is diagnosed later in its evolution compared to females, and it tends to have a worse prognosis, mostly because of the delayed initial diagnosis (4). For this reason, it is important to have a prompt, correct preoperative diagnosis that allows the patient to undergo the appropriate treatment as soon as possible.

In our database, 54 patients underwent both FNAC and TCNB for the assessment of a suspicious breast finding, in order to verify which is the most effective for an early diagnosis of male breast cancer. The mean age of male breast cancer was 65.2 years. This value is similar to the large population-based study of 5494 cases of male breast carcinoma conducted by Anderson et al. (19). 


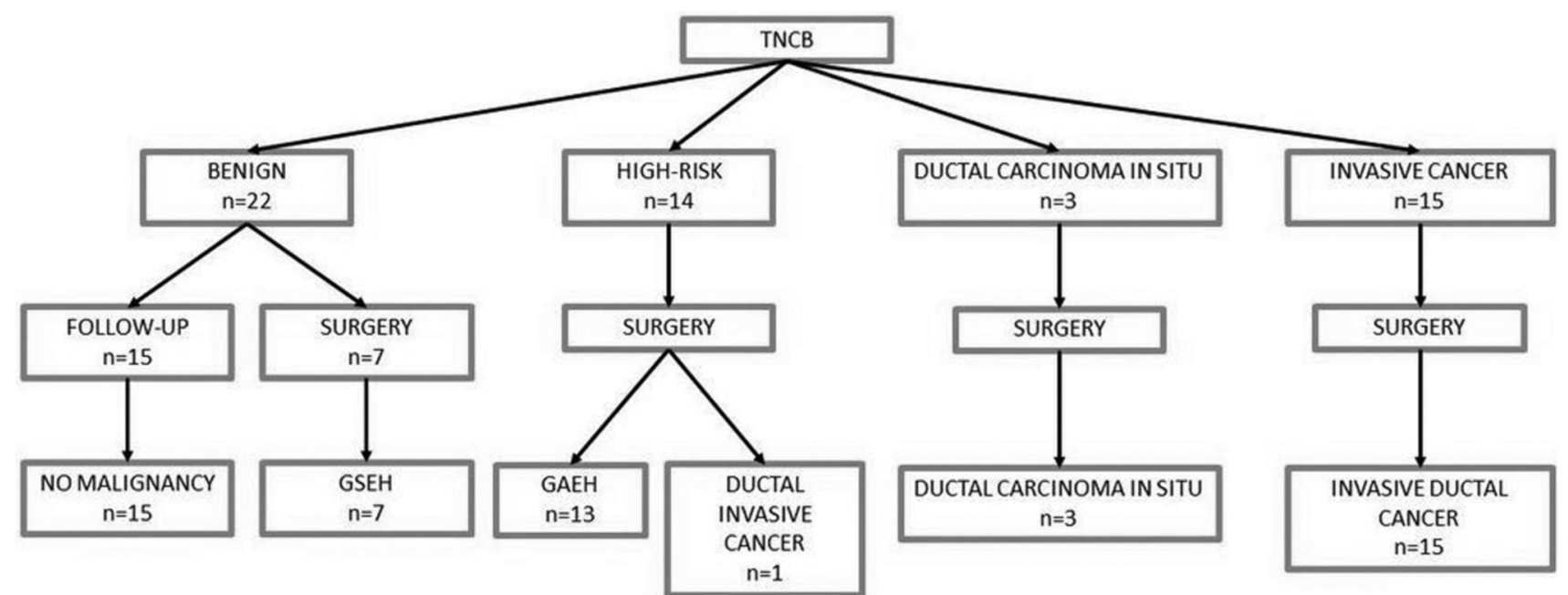

Figure 3. Chart shows the results of ultrasound-guided automated Tru-cut needle biopsy (TCNB) and surgery of the 54 male breast lesions. GAEH, Gynecomastia with simple epithelial hyperplasia; GAEH, gynecomastia with atypical epithelial hyperplasia.

In male patients, a first cytological characterization is usually carried out in the cases reported in the literature (32). In our study, it emerged that FNAC leads to more unsatisfactory results than TCNB $(11.1 \%$ of cases $v s$. no cases, respectively) and this difference was statistically significant. Inadequate sampling by FNAC may be due to sampling error during aspiration, which is also possible in female breast lesions. However, since male breast lesions are in most cases pseudo-nodular areas or areas of structural inhomogeneity, according to US evaluation, in our experience they may be more often subject to errors during sampling with FNAC, even for an experienced operator.

There was no statistically significant difference between the malignancy rate after FNAC and that after TCNB (25.9\% and $33.3 \%$, respectively), although FNAC missed more cancer diagnosis than TCNB (26.1\% vs. 5.3\%). In particular, no DCIS was found after FNAC, instead TCNB was able to correctly identify all DCIS and, although this difference in our small series is not statistically significant, we believe that further prospective studies with a larger cohort should be carried out.

Moreover, one lesion diagnosed as benign after FNAC was actually an IDC after TCNB and it was confirmed by surgery. Wherever possible, a conservative surgical procedure should be preferred, as suggested in the literature (33-37), as it has immunological and time advantages (33, 38). Therefore, if TCNB had not been performed, a malignant lesion would have been addressed to follow-up with a delay in cancer diagnosis. After TCNB, 6 benign lesions classified as atypical/suspicious for malignancy after FNAC were addressed to instrumental follow-up; therefore TCNB avoided surgery in $11.1 \%$ of cases.

On comparison with histological examinations after TCNB, all malignant lesions identified by FNAC were
Table V. Comparison of the number of total malignant lesions, invasive ductal carcinoma and ductal carcinoma in situ identified after fine needle aspiration cytology (FNAC) and Tru-Cut needle biopsy (TCNB) using surgery as the gold standard reference technique $(p<0.05)$.

\begin{tabular}{lccc}
\hline Surgery & FNAC & TCNB & $p$-Value \\
\hline $\begin{array}{l}\text { Total malignant cases } \\
(\mathrm{n}=19 ; 100 \%)\end{array}$ & $\begin{array}{l}73.7 \% \\
(\mathrm{n}=14)\end{array}$ & $\begin{array}{l}94.7 \% \\
(\mathrm{n}=18)\end{array}$ & 0.179 \\
$\begin{array}{c}\text { Invasive ductal carcinoma } \\
(\mathrm{n}=16 ; 84.2 \%)\end{array}$ & $\begin{array}{c}87,5 \% \\
(\mathrm{n}=14)\end{array}$ & $\begin{array}{l}93.8 \% \\
(\mathrm{n}=15)\end{array}$ & 1 \\
$\begin{array}{c}\text { Ductal carcinoma } \text { in situ } \\
(\mathrm{n}=3 ; 15.8 \%)\end{array}$ & $\mathrm{n}=0$ & $\begin{array}{l}100 \% \\
(\mathrm{n}=3)\end{array}$ & 0.1 \\
\hline
\end{tabular}

correctly assessed and they were also confirmed by surgery.

All benign cases after TCNB, addressed to follow-up, remained stable without evidence of malignancy. Moreover, no malignancy was found in the 7 benign lesions that underwent surgery.

In our study, the results of TCNB correlated better with the final histopathology report after surgery than FNAC. In fact, only one high-risk lesion changed pathological results after gold standard evaluation and turned out to be IDC (1.9\%); otherwise, the pathological diagnosis after FNAC changed after surgery for $37.0 \%$ of lesions and this difference was statistically significant.

TCNB avoided $33.3 \%$ of excisional biopsies and therefore unnecessary surgeries without a delay in diagnosis. Compared with surgical biopsies, TCNB is less invasive in terms of cosmesis, with no parenchymal or skin scarring, is faster to perform and has a lower complication rate and cost (36-39). 
Moreover, from the overall experience of our Tertiary Breast Cancer Center, we can confirm that men are less predisposed to undergo breast examination, which creates psychological repercussions in male patients. Local anesthesia is not routinely performed before FNAC, therefore the TCNB was better accepted for the anesthesia used at the site of the sampling, ensuring greater patient compliance in cases of painful lesions. On the other hand, undergoing TCNB after a non-diagnostic cytological result increased the patients' worry. Breast disorders in males can be worrisome both for patients (who feel embarrassed and anxious) and doctors (3940) who might feel uncertain about differentiating a gynaecomastia from a male breast carcinoma.

Histological characterization for immuno-histochemical studies is also essential in large dimension lesions (maximum diameter $>2 \mathrm{~cm}$ ), with a low receptor profile, high proliferative index and high expression of Her2.

In our study, the specificity and sensitivity of FNAC was $73.7 \%$ and $100 \%$, respectively; instead the specificity and sensitivity of TCNB were $94.7 \%$ and $100 \%$, respectively. These data are in line with what the literature reports about the female breast lesions: the sensitivity and specificity of FNAC varies from $77-97 \%$ and $92-99 \%$, respectively (4142). PPV and NPV of FNAC were $100 \%$ and $87.5 \%$ respectively, with an accuracy of $90.7 \%$; instead PPV and NPV of TCNB were $100 \%$ and $97.2 \%$ respectively, with a greater accuracy of $98.1 \%$.

In the absence of standardized diagnostic procedures for the pathological characterization of male breast lesions under instrumental guidance, a histological sampling will always be appropriate. Based on our experience, it should be carried out specifically in cases of strongly suspicious lesions where a multidisciplinary approach to clinical, radiologic and pathologic findings is necessary.

There are some limitations to our study including the small cohort. Moreover, it is a single-institution study; however, our data could be a starting point for multicentric studies with a greater number of cases. Furthermore, for men with a benign histologic diagnosis, directed to instrumental follow-up, only one-year follow-up was considered.

\section{Conclusion}

Our present study shows that both FNAC and TCNB are good tools for the diagnosis of male breast cancer. FNAC leads to a statistically significant higher number of unsatisfactory results and this could lead to increased patient discomfort. Moreover, although there are no significant differences in malignancy detection, FNAC seems more likely to misdiagnose DCIS; further studies are required in this regard. TCNB has a higher specificity and NPV than FNAC and it correlates better with the final histopathology report after surgery than FNAC, avoiding unnecessary surgical excisions, without delay in the diagnosis of male breast cancer. Therefore, we believe that the number of diagnostic surgeries should be reduced, limiting its use in selected cases and preferring the biopsy approach under US guidance for diagnostic purposes.

\section{Conflicts of Interest}

None to be declared.

\section{Authors' Contributions}

Study conception and design: Chiara Adriana Pistolese, Gianluca Vanni, Feliciana Lamacchia; Acquisition of data: Giulia Claroni, Alberto Collura, Materazzo Marco; Analysis of data: Giulia Claroni, Marco Pelicciaro; Interpretation of data: Gianluca Vanni, Chiara Adriana Pistolese, Feliciana Lamacchia; Drafting of article: Feliciana Lamacchia, Michela Censi; Critical revision: Chiara Adriana Pistolese, Gianluca Vanni, Tommaso Perretta.

\section{Acknowledgements}

This study was in part supported by a grant from the Italian Ministry of Health.

\section{References}

1 Yen PP, Sinha N, Barnes PJ, Butt R and Iles S: Benign and malignant male breast diseases: radiologic and pathologic correlation. Can Assoc Radiol J 66: 198-207, 2015. PMID: 26073217. DOI: 10.1016/j.carj.2015.01.002

2 Lattin GE, Jesinger RA, Mattu R and Glassman LM: From the radiologic pathology archives: diseases of the male breast: radiologic-pathologic correlation. Radiographics 33: 461-489, 2013. PMID: 23479708. DOI: 10.1148/rg.332125208

3 Nguyen C, Kettler MD, Swirsky ME, Miller VI, Scott C, Krause $\mathrm{R}$ and Hadro JA: Male breast disease: pictorial review with radiologic-pathologic correlation. Radiographics 33: 763-779, 2013. PMID: 23674773. DOI: 10.1148/rg.333125137

4 Voinea OC, Cîrstoiu MM, Ion D, Sajin M, Dumitrua AV, Patrascu OM, Jingaa DC and Nica AE: Histology of male breast lesions. Series of cases and literature review. Maedica (Buchar) 13(3): 196-201, 2018. PMID: 30568739. DOI: 10.26574/ maedica.2018.13.3.196

5 Yitta S, Singer CI, Toth HB and Mercado CL: Sonographic appearances of benign and malignant male breast disease with mammographic and pathologic correlation. J Ultrasound Med 29: 931-947, 2010. DOI: 10.7863/jum.2010.29.6.931

6 Rosa M and Masood S. Cytomorphology of male breast lesions: diagnostic pitfalls and clinical implications. Diagn Cytopathol 40: 179-184, 2012. PMID: 22246936. DOI: 10.1002/dc.21601

7 Rahmani S, Turton P, Shaaban A and Dall B: Overview of gynecomastia in the modern era and the Leeds Gynaecomastia Investigation algorithm. Breast J 17: 246-55, 2011. PMID: 21477170. DOI: $10.1111 / \mathrm{j} .1524-4741.2011 .01080 . x$

8 Narula HS and Carlson HE: Gynaecomastia-pathophysiology, diagnosis and treatment. Nat Rev Endocrinol 10: 684-698, 2014. PMID: 25112235. DOI: 10.1038/nrendo.2014.139 
9 Önder O, Azizova A, Durhan G, Elibol FD, Akpınar MG and Demirkazık F: Imaging findings and classification of the common and uncommon male breast diseases. Insights Imaging 11(1): 27, 2020. PMID: 32072386. DOI: 10.1186/s13244-0190834-3

10 Chen L, Chantra PK, Larsen LH, Barton P, Rohitopakarn M, Zhu EQ and Bassett LW: Imaging characteristics of malignant lesions of the male breast. Radiographics 26(6): 993-1006, 2006. PMID: 16844928 . DOI: $10.1148 /$ rg.264055116

11 Giordano SH, Cohen DS, Buzdar AU, Perkins G and Hortobagyi GN: Breast carcinoma in men: a population-based study. Cancer 101: 51-57, 2004. PMID: 15221988. DOI: 10.1002/cncr.20312

12 Javidiparsijani S, Rosen LE and Gattuso P: Male breast carcinoma: A clinical and pathological review. Int J Surg Pathol 25(3): 200-205, 2017. PMID: 27831530. DOI: 10.1177/ 1066896916675953

13 Pailoor K, Fernandes H, Jayaprakash CS, Marla NJ and Keshava MS: Fine needle aspiration cytology of male breast lesions - A retrospective study over a six-year period. J Clin Diagn Res 8(10): FC13-FC15, 2014. PMID: 25478347. DOI: 10.7860/ JCDR/2014/10708.4922

14 Adibelli ZH, Oztekin O, Gunhan-Bilgen I, Postaci H, Uslu A and Ilhan E: Imaging characteristics of male breast disease. Breast J 16: 510-518, 2010. DOI: 10.1594/ecr2016/C-1262

15 Orsaria P, Caredda E, Genova F, Materazzo M, Capuano I, Vanni G, Granai AV, DE Majo A, Portarena I, Sileri P, Petrella G, Palombi L and Buonomo OC: Additional nodal disease prediction in breast cancer with sentinel lymph node metastasis based on clinicopathological features. Anticancer Res 38(4): 2109-2117, 2018. PMID: 29599329. DOI: 10.21873/anticanres.12451

16 Orsaria P, Varvaras D, Vanni G, Pagnani G, Scaggiante J, Frusone F, Granai AV, Petrella D and Buonomo OC: Nodal status assessment in breast cancer: Strategies of clinical grounds and quality of life implications. Int J Breast Cancer 2014: 469803, 2014. PMID: 24672730. DOI: $10.1155 / 2014 / 469803$

17 Ielpo B, Pernaute AS, Elia S, Buonomo OC, Valladares LD, Aguirre EP, Petrella G and Torres Garcia A: Impact of number and site of lymph node invasion on survival of adenocarcinoma of esophagogastric junction. Interact Cardiovasc Thorac Surg 10: 704-708, 2010. PMID: 20154347. DOI: 10.1510/icvts. 2009.222778

18 Ferroni P, Roselli M, Spila A, D’Alessandro R, Portarena I, Mariotti S, Palmirotta R, Buonomo O, Petrella G and Guadagni F: Serum sE-selectin levels and carcinoembryonic antigen mRNA-expressing cells in peripheral blood as prognostic factors in colorectal cancer patients. Cancer 116: 2913-2921, 2010. PMID: 20336782. DOI: 10.1002/cncr.25094

19 Ielpo B, Mazzetti C, Venditti D, Buonomo O and Petrella G: A case of metachronous splenic metastasis from renal cell carcinoma after 14 years. Int J Surg 8: 353-355, 2010. PMID: 20438874. DOI: 10.1016/j.ijsu.2010.04.006

20 Weiss JR, Moysich KB and Swede H: Epidemiology of male breast cancer. Cancer Epidemiol Biomarkers Prev 14(1): 20-26, 2005. PMID: 15668471.

21 Giordano SH: Breast cancer in men. N Engl J Med 378: 23112320, 2018. PMID: 29897847. DOI: 10.1056/NEJMra1707939

22 Anderson WF, Jatoi I, Tse J and Rosenberg PS: Male breast cancer: a population-based comparison with female breast cancer. J Clin Oncol 28: 232-239, 2010. PMID: 19996029. DOI: 10.1200/JCO.2009.23.8162
23 Expert Panel on Breast Imaging, Niell BL, Lourenco AP, Moy L, Baron P, Didwania AD, diFlorio-Alexander RM, Heller SL, Holbrook AI, Le-Petross HT, Lewin AA, Mehta TS, Slanetz PJ, Stuckey AR, Tuscano DS, Ulaner GA, Vincoff NS, Weinstein SP and Newell MS: ACR Appropriateness Criteria ${ }^{\circledR}$ Evaluation of the symptomatic male breast. J Am Coll Radiol 15(11S): S313S320, 2018. PMID: 30392600. DOI: 10.1016/j.jacr.2018.09.017

24 Patterson SK, Helvie MA, Aziz K and Nees AV: Outcome of men presenting with clinical breast problems: the role of mammography and ultrasound. Breast J 12: 418-423, 2006. PMID: 16958958. DOI: 10.1111/j.1075-122X.2006.00298.x

25 D'Orsi CJ, Sickles EA, Mendelson EB and Morris EA: ACR BIRADS Atlas, Breast Imaging Reporting and Data System. Reston, VA: American College of Radiology, 2013.

26 Khalkhali I and Cho J: Male breast cancer imaging. Breast J 3: 217-218, 2015. PMID: 25900306. DOI: 10.1111/tbj.12399

27 Shashirekha CA, Rahul Singh R, Ravikiran HR, Sreeramulu PN and Prasad K: Fine needle aspiration cytology versus trucut biopsy in the diagnosis of breast cancer: a comparative study. Int Surg J 4(11): 3718-3721, 2017. DOI: 10.18203/2349-2902. isj20174893

28 Perry N, Broeders M, de Wolf C, Törnberg S, Holland R and Von Karsa L: European guidelines for quality assurance in breast cancer screening and diagnosis. Fourth Edition. Ann Oncol 19(4): 614-622, 2008. PMID: 18024988. DOI: 10.1093/annonc/ $\mathrm{mdm} 481$

29 Lilleng R, Paksoy N, Vural G, Langmark F and Hagmar B: Assesment of fine needle aspiration cytology and histopathology for diagnosing male breast masses. Acta Cytol 39: 877-881, 1995. PMID: 7571963.

30 Amrikachi M, Green LK, Rone R and Ramzy I: GynecomastiaCytologic features and diagnostic pitfalls in fine needle aspirates. Acta Cytol 45(6): 948-952, 2001. PMID: 11726123. DOI: $10.1159 / 000328369$

31 Perretta T, Lamacchia F, Ferrari D, Beninati E, DI Tosto F, De Stasio V, Meucci R, Di Stefano C, Buonomo OC, Vanni G and Pistolese CA: Evaluation of ultrasound-guided 8-gauge vacuumassisted excision system for the removal of US-detectable breast lesions. Anticancer Res 40(3): 1719-1729, 2020. PMID: 32132080. DOI: 10.21873/anticanres.14125

32 Joshi A, Kapila K and Verma K: Fine needle aspiration cytology of male breast masses- nineteen years of experience. Acta Cytol 43: 334-338, 1999. PMID: 10349358. DOI: 10.1159/000331077

33 Vanni G, Materazzo M, Perretta T, Meucci R, Anemona L, Buonomo C, Mario Dauri, Granai AV, Rho M, Ingallinella S, Tacconi F, Ambrogi V, Chiaravalloti A, Schillaci O, Petrella G and Buonomo OC: Impact of awake breast cancer surgery on postoperative lymphocyte responses. In Vivo 33: 1879-1884, 2019. PMID: 31662515 . DOI: $10.21873 /$ invivo.11681

34 Calì Cassi L, Biffoli F, Francesconi D, Petrella G and Buonomo $\mathrm{O}$ : Anesthesia and analgesia in breast surgery: the benefits of peripheral nerve block. Eur Rev Med Pharmacol Sci 21: 13411345, 2017. PMID: 28387892.

35 Mineo TC, Sellitri F, Vanni G, Gallina FT and Ambrogi V: Immunological and inflammatory impact of non-intubated lung metastasectomy. Int J Mol Sci 18(7): 1466, 2017. PMID: 28686211. DOI: $10.3390 / \mathrm{ijms} 18071466$

36 Calì Cassi L, Vanni G, Petrella G, Orsaria P, Pistolese C, Lo Russo G, Innocenti M and Buonomo O: Comparative study of oncoplastic versus non-oncoplastic breast conserving surgery in 
a group of 211 breast cancer patients. Eur Rev Med Pharmacol Sci 20: 2950-2954, 2016. PMID: 27460720.

37 Pistolese CA, Ciarrapico A, Perretta T, Cossu E, Della Gatta F, Giura S, Caramanica C and Simonetti G: Cost-effectiveness of two breast biopsy procedures: Surgical biopsy versus vacuumassisted biopsy. Radiol Med 117: 539-5579, 2012. PMID: 22020428. DOI: $10.1007 / \mathrm{s} 11547-011-0735-0$

38 Marzocchella L, Sini V, Buonomo O, Orlandi A, Masuelli L, Bonanno E, Lista F, Turriziani M, Manzari V, Roselli M, Modesti A and Bei R: Spontaneous immunogenicity of ribosomal P0 protein in patients with benign and malignant breast lesions and delay of mammary tumor growth in P0vaccinated mice. Cancer Sci 102: 509-515, 2011. PMID: 21175994. DOI: 10.1111/j.1349-7006.2010.01814.x

39 Chiricozzi A, Faleri S, Saraceno R, Bianchi L, Buonomo O, Chimenti S and Chimenti MS: Tofacitinib for the treatment of moderate-to-severe psoriasis. Expert Rev Clin Immunol 11: 443455, 2015. PMID: 25666451. DOI: 10.1586/1744666x.2015. 1013534
40 Schanz S, Schreiber G, Zitzmann M, Krapohl BD, Horch R and Köhn FM: S1 guidelines: Gynecomastia in adults. JDDG 4: 465472, 2017. PMID: 28378479. DOI: $10.1111 /$ ddg. 13080

41 Pistolese CA, Tosti D, Citraro D, Ricci F, Di Stefano C, Lamacchia F, Ferrari D and Floris R: Probably benign breast nodular lesions (BI-RADS 3): Correlation between ultrasound features and histologic findings. Ultrasound Med Biol 45(1): 7884, 2019. PMID: 30340921. DOI: 10.1016/j.ultrasmedbio. 2018.09.004

42 Mitra S and Dey P: Fine-needle aspiration and core biopsy in the diagnosis of breast lesions: A comparison and review of the literature. Cytojournal 13: 18, 2016. PMID: 27651820. DOI: 10.4103/1742-6413.189637

Received June 22, 2020

Revised July 27, 2020

Accepted July 28, 2020 